\title{
High-quality permanent draft genome sequence of the extremely osmotolerant diphenol degrading bacterium Halotalea alkalilenta AW-7', and emended description of the genus Halotalea
}

\author{
Spyridon Ntougias' ${ }^{1}$, Alla Lapidus ${ }^{2,3}$, Alex Copeland ${ }^{4}$, T. B. K. Reddy ${ }^{4}$, Amrita Pati ${ }^{4}$, Natalia N. Ivanova ${ }^{4}$, \\ Victor M. Markowitz ${ }^{5}$, Hans-Peter Klenk ${ }^{6}$, Tanja Woyke ${ }^{4}$, Constantinos Fasseas ${ }^{7}$, Nikos C. Kyrpides ${ }^{4,8}$ \\ and Georgios I. Zervakis ${ }^{9^{*}}$
}

\begin{abstract}
Members of the genus Halotalea (family Halomonadaceae) are of high significance since they can tolerate the greatest glucose and maltose concentrations ever reported for known bacteria and are involved in the degradation of industrial effluents. Here, the characteristics and the permanent-draft genome sequence and annotation of Halotalea alkalilenta AW- $7^{\top}$ are described. The microorganism was sequenced as a part of the Genomic Encyclopedia of Type Strains, Phase l: the one thousand microbial genomes (KMG) project at the DOE Joint Genome Institute, and it is the only strain within the genus Halotalea having its genome sequenced. The genome is $4,467,826 \mathrm{bp}$ long and consists of 40 scaffolds with $64.62 \%$ average GC content. A total of 4,104 genes were predicted, comprising of 4,028 protein-coding and 76 RNA genes. Most protein-coding genes (87.79 \%) were assigned to a putative function. Halotalea alkalilenta $\mathrm{AW}-7^{\top}$ encodes the catechol and protocatechuate degradation to $\beta$-ketoadipate via the $\beta$-ketoadipate and protocatechuate ortho-cleavage degradation pathway, and it possesses the genetic ability to detoxify fluoroacetate, cyanate and acrylonitrile. An emended description of the genus Halotalea Ntougias et al. 2007 is also provided in order to describe the delayed fermentation ability of the type strain.
\end{abstract}

Keywords: Alkaline two-phase olive mill waste, Halomonadaceae, Protocatechuate ortho-cleavage, Catechol to $\beta$-ketoadipate degradation pathway, Cyanate and acrylonitrile detoxification, GEBA-KMG

\section{Introduction}

The genus Halotalea includes a single species, i.e., H. alkalilenta, which is a motile, rod-shaped, alkalitolerant and halotolerant Gram-negative staining heterotrophic bacterium [1]. Strain AW $-7^{\mathrm{T}}\left(=\mathrm{DSM} 17697^{\mathrm{T}}=\right.$ CECT $7134^{\mathrm{T}}=\mathrm{CIP}$ $\left.109710^{\mathrm{T}}\right)$ is the type species of the genus Halotalea and of the type strain of the species $H$. alkalilenta [1]. The strain was isolated from alkaline olive mill waste, which was generated by a two-phase centrifugal olive oil extraction system located in the Toplou Monastery area, Sitia, Crete [1]. The Neo-Latin genus name derived from the Greek and the

\footnotetext{
* Correspondence: zervakis@aua.gr

${ }^{9}$ Laboratory of General and Agricultural Microbiology, Agricultural University of Athens, Athens, Greece

Full list of author information is available at the end of the article
}

Latin nouns halos and talea, meaning salt-living and rodshaped cells, respectively. The Neo-Latin species epithet halotalea composed of the Arabic term al qaliy and the Latin epithet lentus (a), meaning alkali and slow respectively which refer to slowly-growing cells under alkaline conditions (alkalitolerant) [1].

Halotalea alkalilenta belongs to the family Halomonadaceae [1-4], which has accommodated in chronological order the genera Halomonas [5], Chromohalobacter [6], Zymobacter [7], Carnimonas [8], Cobieta [9], Halotalea [1], Modicisalibacter [4], Salinicola [10], Kushneria [11], Aidingimonas [12] and Larsenimonas [13-15]. By employing multilocus sequence analysis, de la Haba et al. [16] found that all genera of the family Halomonadaceae, apart from Halomonas and Modicisalibacter, are 
phylogenetically distinct. Carnimonas nigrificans and Zymobacter palmae are the closest phylogenetic relatives of $H$. alkalilenta, and were isolated from cured meat and palm sap respectively $[7,8]$. $H$. alkalilenta differs from C. nigrificans in its higher DNA $\mathrm{G}+\mathrm{C}$ content and salt upper limit for growth, colony color, motility, its ability to grow at $5{ }^{\circ} \mathrm{C}$ and $37{ }^{\circ} \mathrm{C}$, to utilize mannitol, in its inability to hydrolyze starch, to deaminize phenylalanine and to produce acids from D-mannitol and sucrose, in the proportion of the major membrane fatty acids and in the presence/absence of $\mathrm{C}_{10: 0}, \mathrm{C}_{12: 0}, \mathrm{C}_{12: 02} \mathrm{OH}, \mathrm{C}_{14: 0}, \mathrm{C}_{16: 0}$ 3-OH, cyclo- $\mathrm{C}_{17: 0}, \mathrm{C}_{18: 0}$ and $\mathrm{C}_{18: 1} \mathrm{t} 9[1,8]$. H. alkalilenta can be distinguished from $Z$. palmae in its higher DNA $\mathrm{G}+\mathrm{C}$ content, colony color, $\mathrm{pH}$ and emperature range for growth, optimum growth temperature, its higher Dglucose tolerance, its ability to utilize citrate, its inability to give positive methyl red and Voges-Proskauer reactions, in the proportion of the major membrane fatty acids and in the presence/absence of $\mathrm{C}_{10: 0}, \mathrm{C}_{10: 0} 3-\mathrm{OH}, \mathrm{C}_{12: 0} 2-\mathrm{OH}$, $\mathrm{C}_{15: 0}, \mathrm{C}_{17: 0}$, cyclo- $\mathrm{C}_{17: 0}, \mathrm{C}_{18: 1} \omega 9$ and $\mathrm{C}_{18: 1} \omega 7[1,7]$.

Here, a summarized classification and key characteristics are presented for $H$. alkalilenta AW- $7^{\mathrm{T}}$, together with the description of the high-quality permanent draft genome sequence and annotation.

\section{Organism information}

\section{Classification and features}

The 16S rRNA gene sequence of $H$. alkalilenta AW- $7^{\mathrm{T}}$ was compared using NCBI BLAST under default settings (e.g., considering only the high-scoring segment pairs (HSPs) from the best 250 hits) with the most recent release of the Greengenes database [17] and the relative frequencies of taxa and keywords (reduced to their stem [18]) were determined and weighted by BLAST scores. The frequency of genera that belonged to the family Halomonadaceae was $95.2 \%$. The closest match of $H$. alkalilenta AW- $7^{\mathrm{T}}$ in $16 \mathrm{~S}$ rRNA gene, submitted in INSDC (=EMBL/NCBI/DDBJ) under the accession number DQ421388 (=NR_043806), were Zymobacter palmae ATCC 51623 ${ }^{\mathrm{T}}$ (NR_041786) [7] and Carnimonas nigrifaciens $\mathrm{CTCBS1}^{\mathrm{T}}$ (NR_029342) [8] showing BLAST similarities of $96.2 \%$ and $95.3 \%$ respectively and HSP coverages of $99.7 \%$ and $100 \%$ respectively.

Figure 1 shows the phylogenetic allocation of $H$. alkalilenta $\mathrm{AW}-7^{\mathrm{T}}$ within the family Halomonadaceae in a $16 \mathrm{~S}$ rRNA gene sequence-based tree. The sequence of the only 16S rRNA gene copy in the genome differs by 5 nucleotides from the previously published 16S rRNA sequence (DQ421388= NR_043806, coverage 95.0\%).

H. alkalilenta $\mathrm{AW}-7^{\mathrm{T}}$ is a Gram-negative motile rodshaped bacterium [1] with a length of 1.4-2.1 $\mu \mathrm{m}$ and a width of 0.6-0.9 $\mu \mathrm{m}$ (Table 1 and Fig. 2). The temperature range for growth is $5-45^{\circ} \mathrm{C}$, with an optimum temperature for growth at $32-37^{\circ} \mathrm{C}[1]$. H. alkalilenta $\mathrm{AW}-7^{\mathrm{T}}$ is halotolerant and alkalitolerant, growing at salinity and $\mathrm{pH}$ ranges of $0-150 \mathrm{~g} \mathrm{~L}^{-1} \mathrm{NaCl}$ and 5-11, respectively [1]. The optimum salt and $\mathrm{pH}$ for growth are $0-3 \% \mathrm{w} / \mathrm{v} \mathrm{NaCl}$ and 7, respectively [1].

H. alkalilenta $\mathrm{AW}-7^{\mathrm{T}}$ is a non-denitrifying chemoorganotroph; it utilizes mostly L-glutamine and L-proline, followed by D-galactose, D-glucose, glycerol, D-mannitol, protocatechuate, L-serine, succinate and sucrose, while it grows weakly on acetate, citrate, D-fructose, maltose, sorbitol and gallate [1]. H. alkalilenta AW- $7^{\mathrm{T}}$ also produces acid aerobically from $\mathrm{D}$-fructose, $\mathrm{D}$-galactose, $\mathrm{D}$-glucose, maltose, D-mannose and melibiose, and hydrolyses Tween 20 [1]. Despite the fact that urea hydrolysis is encoded in $H$. alkalilenta $\mathrm{AW}-7^{\mathrm{T}}$ genome, no positive reaction was detected by Ntougias et al. [1] and the present study (using the EnteroPluri-Test). H. alkalilenta $\mathrm{AW}-7^{\mathrm{T}}$ is susceptible to kanamycin, polymixin $\mathrm{B}$, rifampicin, streptomycin and tetracycline (50 $\mathrm{mg} \mathrm{L}^{-1}$ each) [1].

In the past, $H$. alkalilenta $\mathrm{AW}-7^{\mathrm{T}}$ and $C$. nigrificans $\mathrm{CTCBS1}^{\mathrm{T}}$ were reported as oxidase positive $[1,8]$. However, genome comparisons showed that both $H$. alkalilenta AW- $7^{\mathrm{T}}$ and $C$. nigrificans $\mathrm{CTCBS1} 1^{\mathrm{T}}$ possessed an identical oxidative phosphorylation pathway that lacks cytochrome c oxidase, which was distinct from that of $Z$. palmae $\mathrm{T} 109^{\mathrm{T}}$. In addition, no fermentation ability was previously detected for $H$. alkalilenta AW- $7^{\mathrm{T}}$ using standard incubation periods [1], although the pyruvate fermentation to acetate II MetaCyc pathway is encoded in both H. alkalilenta $\mathrm{AW}-7^{\mathrm{T}}$ and $Z$. palmae $\mathrm{T} 109^{\mathrm{T}}$. For this reason, the fermentation ability of $H$. alkalilenta AW- $7^{\mathrm{T}}$ was re-examined under prolonged incubation period using the EnteroPluri-Test (BD, USA). No fermentation reaction was observed for incubations up to 4-days, although, thereafter, a positive reaction was obtained for glucose (at the 5th day of incubation, without gas production) and dulcitol (at 9th day of incubation). H. alkalilenta AW- $7^{\mathrm{T}}$ could not ferment adonitol, lactose, arabinose and sorbitol after a 9-days incubation period. In agreement to what was previously reported by Ntougias et al. [1], no growth of $H$. alkalilenta AW $-7^{\mathrm{T}}$ was observed in the present study on yeast extract-peptone-glucose agar plates placed for an incubation period of 1 month in an anaerobic jar containing the Anaerocult A system (Merck). However, exposure of culture plates to oxygen led to fastidious growth. In this sense, it is concluded that $H$. alkalilenta AW- $7^{\mathrm{T}}$ can tolerate anaerobic conditions through a slow fermentation mechanism.

\section{Chemotaxonomy}

The main membrane fatty acids of $H$. alkalilenta AW- $7^{\mathrm{T}}$ are in the descending order of concentration: $\mathrm{C}_{18: 1} \omega 7 \mathrm{c}$, $\mathrm{C}_{16: 0}, \mathrm{C}_{19: 0}$ cyclo $\omega 8 \mathrm{c}, \mathrm{C}_{12: 0} \mathrm{3}-\mathrm{OH}$ and $\mathrm{C}_{16: 1} \omega 7 \mathrm{c}$ /iso-C15:0 2-OH [1]. The only respiratory quinone found in $H$. alkalilenta $\mathrm{AW}-7^{\mathrm{T}}$ is ubiquinone-9 $[1]$. 


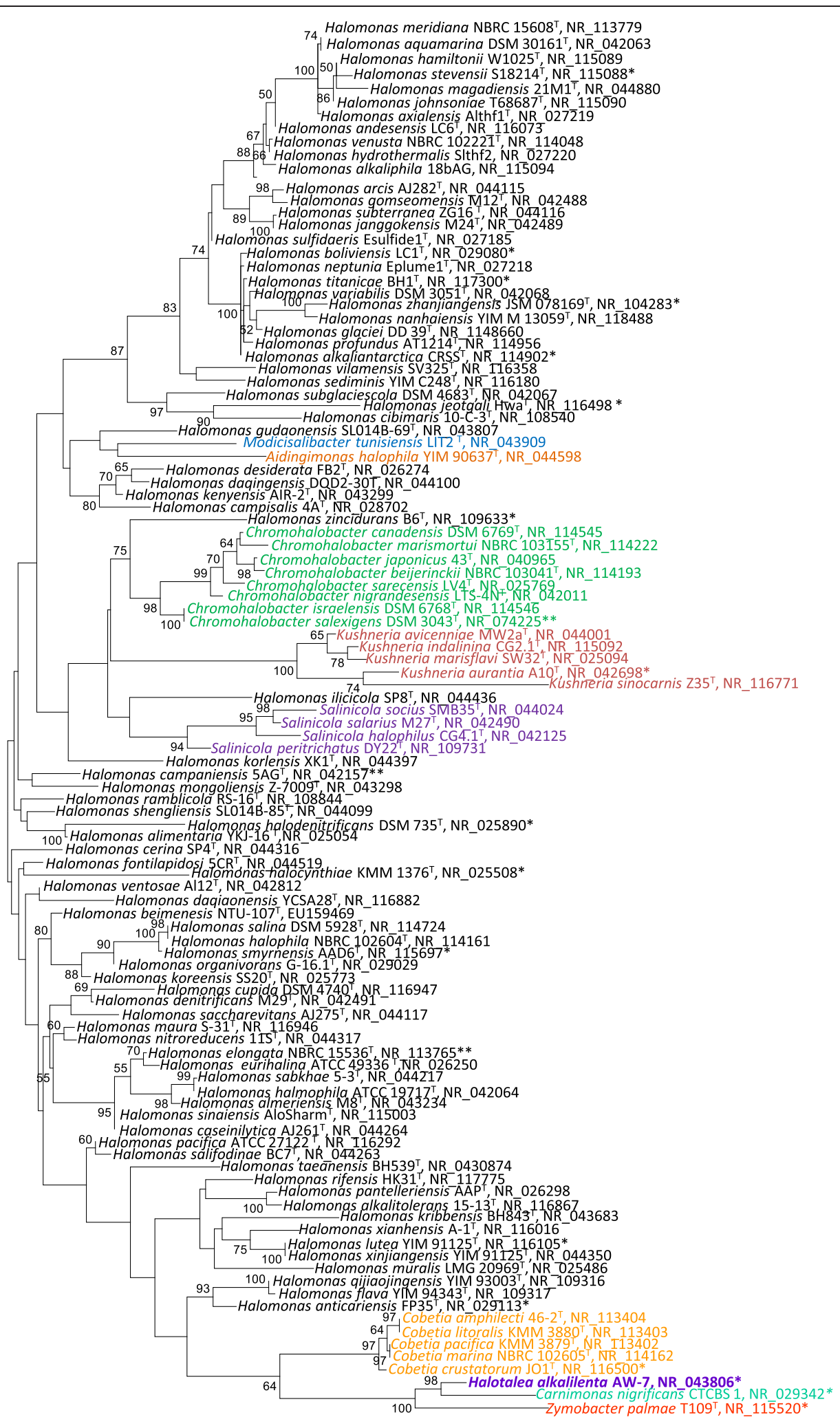

Fig. 1 (See legend on next page.) 
(See figure on previous page.)

Fig. 1 Phylogenetic tree displaying the position of $H$. alkalilenta AW- $7^{\top}$ among the type strains of other species within the Halomonadaceae. The tree was inferred from 1152 aligned characters [38, 39] of the 165 rRNA gene sequence under the maximum likelihood (ML) criterion [40]. Tree branches are constructed on the basis of the expected number of substitutions per site. Values above branches denote support values from 100 ML bootstrap replicates [41]. Members of different genera within the Halomonadaceae are depicted in different fonts color. Lineages with strain genome sequencing projects registered in GOLD [24] are labeled with one asterisk, and those also listed as 'Complete and Published' with two asterisks

\section{Genome sequencing and annotation}

\section{Genome project history}

H. alkalilenta $\mathrm{AW}-7^{\mathrm{T}}$ was selected for sequencing on the basis of its phylogenetic position [19-21], and is part of Genomic Encyclopedia of Type Strains, Phase I: the one thousand microbial genomes project [22] which aims not only to increase the sequencing coverage of key reference microbial genomes [23]. The genome project is accessible in the Genomes On Line Database [24] and the entire genome sequence is deposited in GenBank.

Table 1 Classification and general features of Halotalea alkalilenta strain AW-7 ${ }^{\top}$ according to the MIGS recommendations [42], published by the Genome Standards Consortium [43] and the Names for Life database [44]

\begin{tabular}{|c|c|c|c|}
\hline MIGS ID & Property & Term & Evidence code $\mathrm{e}^{\mathrm{a}}$ \\
\hline & Classification & Domain Bacteria & TAS [45] \\
\hline & & Phylum Proteobacteria & $\operatorname{TAS}[46,47]$ \\
\hline & & Class Gammaproteobacteria & TAS [47-49] \\
\hline & & Order Oceanospirillales & $\operatorname{TAS}[47,50]$ \\
\hline & & Family Halomonadaceae & $\operatorname{TAS}[1-4,51]$ \\
\hline & & Genus Halotalea & TAS [1] \\
\hline & & Species Halotalea alkalilenta & TAS [1] \\
\hline & & Type strain: $A W-T^{\top}$ & TAS [1] \\
\hline & Gram stain & negative & TAS [1] \\
\hline & Cell shape & rod & TAS [1] \\
\hline & Motility & motile & TAS [1] \\
\hline & Sporulation & non-sporulating & TAS [1] \\
\hline & Temperature range & $5-45^{\circ} \mathrm{C}$ & TAS [1] \\
\hline & Optimum temperature & $32-37^{\circ} \mathrm{C}$ & TAS [1] \\
\hline & $\mathrm{pH}$ range; Optimum & $5-11 ; 7$ & TAS [1] \\
\hline & Carbon source & $\begin{array}{l}\text { carbohydrates, amino-acids, } \\
\text { organic acid anions and } \\
\text { alcohols }\end{array}$ & TAS [1] \\
\hline MIGS-6 & Habitat & olive mill waste & TAS [1] \\
\hline MIGS-6.3 & Salinity & up to $15 \% \mathrm{NaCl} w / \mathrm{v}$ & TAS [1] \\
\hline MIGS-22 & Oxygen requirement & facultatively anaerobic & IDA \\
\hline MIGS-15 & Biotic relationship & free-living & TAS [1] \\
\hline \multirow[t]{2}{*}{ MIGS-14 } & Pathogenicity & none & NAS \\
\hline & Biosafety level & 1 & TAS [52] \\
\hline MIGS-4 & Geographic location & $\begin{array}{l}\text { Greece, Crete, Toplou } \\
\text { Monastery }\end{array}$ & TAS [1] \\
\hline MIGS-5 & Sample collection & 2003 & NAS \\
\hline MIGS-4.1 & Latitude & 35.220 & TAS [1] \\
\hline MIGS-4.2 & Longitude & 26.216 & TAS [1] \\
\hline MIGS-4.3 & Depth & surface & NAS \\
\hline MIGS-4.4 & Altitude & $161 \mathrm{~m}$ & NAS \\
\hline
\end{tabular}

${ }^{a}$ Evidence codes - IDA: Inferred from Direct Assay; TAS: Traceable Author Statement (i.e., a direct report exists in the literature); NAS: Non-traceable Author Statement (i.e., not directly observed for the living, isolated sample, but based on a generally accepted property for the species, or anecdotal evidence). These evidence codes are from the Gene Ontology project [53] 


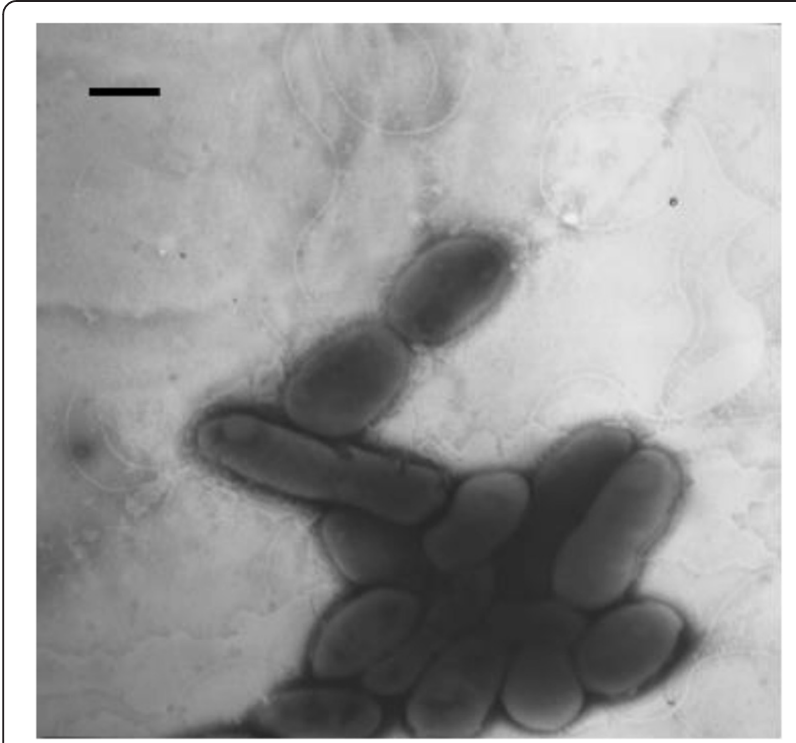

Fig. 2 Electron micrograph of negatively-stained $H$. alkalilenta AW-7 cells. Bar denotes $1 \mu \mathrm{m}$

Sequencing, finishing and annotation were accomplished by the DOE Joint Genome Institute [25] using state of the art genome sequencing technology [26]. The project information is summarized in Table 2.

\section{Growth conditions and genomic DNA preparation}

$H$. alkalilenta AW $-7^{\mathrm{T}}$ was cultivated aerobically in trypticase soy yeast extract medium at $28{ }^{\circ} \mathrm{C}$. Genomic DNA was obtained using the Invitrogen PureLink ${ }^{\bullet}$ Genomic DNA Mini Kit (Life Technologies Inc.) following the standard protocol. In addition, DNA prepared by the DSMZ is available via the DNA Bank Network [27].

\section{Genome sequencing and assembly}

The draft genome of was generated at the DOE Joint Genome Institute using the Illumina technology [28].
An Illumina std shotgun library was constructed and sequenced using the Illumina HiSeq 2000 platform which generated 13,537,536 reads totaling 2,030.6 Mb. All general aspects of library construction and sequencing performed can be found at JGI website [29]. All raw Illumina sequence data was passed through DUK, a filtering program developed at JGI, which removes known Illumina sequencing and library preparation artifacts (Mingkun L, et al., unpublished). Following steps were then performed for assembly: (1) filtered Illumina reads were assembled using Velvet (version 1.2.07) [30], (2) 1-3 kb simulated paired end reads were created from Velvet contigs using wgsim [31], (3) Illumina reads were assembled with simulated read pairs using Allpaths-LG (version r46652) [32]. Parameters for assembly steps were: 1) Velvet (velveth: 63 -shortPaired and velvetg: -very clean yes -exportFiltered yes -min contig lgth 500 -scaffolding no -cov cutoff 10) 2) wgsim (-e 0 -1 100 -2 100 -r 0 -R 0 -X 0) 3) Allpaths-LG (PrepareAllpathsInputs:PHRED 64 = 1 PLOIDY = 1 FRAG COVERAGE $=125$ JUMP COVERAGE $=25$ LONG JUMP COV $=50, \quad$ RunAllpathsLG: $\quad$ THREADS $=8 \quad$ RUN $=$ std shredpairs TARGETS $=$ standard VAPI WARN ONLY = True OVERWRITE = True). The final draft assembly contained 56 contigs in 40 scaffolds, totaling $4.5 \mathrm{~Kb}$ in size. The final assembly was based on 1,500.0 Mb of Illumina data. Based on a presumed genome size of $5.0 \mathrm{Mb}$, the average input read coverage used for the assembly was $300.0 \times$.

\section{Genome annotation}

Genes were detected using the Prodigal software [33] at the DOE-JGI Genome Annotation pipeline [34, 35]. The CDSs predicted were translated and searched against the National Center for Biotechnology Information nonredundant database, UniProt, TIGRFam, Pfam, PRIAM, KEGG, COG, and InterPro databases. Additional gene prediction and functional annotation analysis was carried

Table $2 \mathrm{H}$. alkalilenta AW-7 ${ }^{\top}$ genome sequencing project details

\begin{tabular}{lll}
\hline MIGS ID & Property & Term \\
\hline MIGS-31 & Finishing quality & High-Quality Draft \\
MIGS-29 & Sequencing platforms & Illumina HiSeq 2000 \\
MIGS-31.2 & Sequencing coverage & $300 \times$ \\
MIGS-30 & Assemblers & vpAllpaths v. r46652 \\
MIGS-32 & Gene calling method & Prodigal 2.5 \\
& INSDC ID & JHYY00000000 \\
& Genbank Date of Release & May 5, 2014 \\
& GOLD ID & Gp0040002 \\
& NCBI project ID & 221047 \\
MIGS-13 & Source material identifier & DSM 17697 \\
& Project relevance & GEBA-KMG, Tree of Life, Biodegradation, Extremophiles \\
\hline
\end{tabular}


out in the Integrated Microbial Genomes - Expert Review platform [36]. The genome sequence and the annotations described in this paper are available from the Integrated Microbial Genome system [37].

\section{Genome properties}

The genome is $4,467,826$ bp long and comprised of 40 scaffolds with $64.62 \%$ average GC content (Table 3). A total of 4,104 genes were predicted, consisting of 4,028 protein-coding and 76 RNA genes. The majority of protein-coding genes $(87.79 \%)$ were assigned to a putative function, whereas the remaining ones were annotated as hypothetical proteins. Distribution of genes into COGs functional categories is displayed in Table 4.

\section{Insights into the genome sequence}

The genome size of $H$. alkalilenta AW- $7^{\mathrm{T}}(4.47 \mathrm{Mbp})$ is $50 \%$ and $60 \%$ greater than those of Z. palmae $\mathrm{T} 109^{\mathrm{T}}$ and C. nigrificans $\mathrm{CTCBS1}^{\mathrm{T}}$ (2.73 and $2.98 \mathrm{Mbp}$ ) respectively. In $H$. alkalilenta AW- $7^{\mathrm{T}}$, protein coding genes involved in the major functional categories (i.e., amino acid, carbohydrate and lipid metabolism, membrane transport, energy metabolism) are $50 \%$ and $30 \%$ greater in number than those detected in Z. palmae $\mathrm{T} 109^{\mathrm{T}}$ and C. nigrificans $\mathrm{CTCBS1}^{\mathrm{T}}$, respectively. Moreover, genes encoding xenobiotic metabolic proteins are $69 \%$ and $57 \%$ more in $H$. alkalilenta AW- $7^{\mathrm{T}}$ than those identified in $\mathrm{Z}$. palmae $\mathrm{T} 109^{\mathrm{T}}$ and C. nigrificans $\mathrm{CTCBS}^{\mathrm{T}}$ respectively.

Genome data uncovered the genetic ability of $H$. alkalilenta $\mathrm{AW}-7^{\mathrm{T}}$ to degrade several recalcitrant substrates.

\begin{tabular}{lrc} 
Table 3 Genome statistics & & \\
\hline Attribute & \multicolumn{1}{l}{ Value } & \% of Total \\
\hline Genome size (bp) & $4,467,826$ & 100.00 \\
DNA coding region (bp) & $3,922,088$ & 87.79 \\
DNA G + C content (bp) & $2,887,209$ & 64.62 \\
DNA scaffolds & 40 & \\
Total genes & 4,104 & 100.00 \\
RNA genes & 76 & 1.85 \\
tRNA genes & 52 & 1.27 \\
Protein-coding genes & 4,028 & 98.15 \\
Pseudo genes & 0 & 0.00 \\
Genes with function prediction & 3,603 & 87.79 \\
(proteins) & & \\
Genes in paralog clusters & 3,380 & 82.36 \\
Genes assigned to COGs & 3,246 & 79.09 \\
Genes assigned Pfam domains & 3,637 & 88.62 \\
Genes with signal peptides & 343 & 8.36 \\
Genes with transmembrane helices & 905 & 22.05 \\
CRISPR repeats & 3 & \\
\hline
\end{tabular}

${ }^{a}$ The total is based on either the size of the genome in base pairs or the total number of protein coding genes in the annotated genome
Table 4 Number of genes associated with the general COG functional categories

\begin{tabular}{|c|c|c|c|}
\hline Code & Value & $\%$ Age & Description \\
\hline J & 188 & 5.15 & $\begin{array}{l}\text { Translation, ribosomal structure and } \\
\text { biogenesis }\end{array}$ \\
\hline A & 1 & 0.03 & RNA processing and modification \\
\hline K & 313 & 8.58 & Transcription \\
\hline$L$ & 124 & 3.40 & Replication, recombination and repair \\
\hline B & 3 & 0.08 & Chromatin structure and dynamics \\
\hline $\mathrm{D}$ & 30 & 0.82 & $\begin{array}{l}\text { Cell cycle control, cell division, } \\
\text { chromosome partitioning }\end{array}$ \\
\hline V & 29 & 0.79 & Defense mechanisms \\
\hline $\mathrm{T}$ & 125 & 3.42 & Signal transduction mechanisms \\
\hline M & 169 & 4.63 & Cell wall/membrane biogenesis \\
\hline $\mathrm{N}$ & 58 & 1.59 & Cell motility \\
\hline U & 56 & 1.53 & $\begin{array}{l}\text { Intracellular trafficking, secretion and } \\
\text { vesicular transport }\end{array}$ \\
\hline $\mathrm{O}$ & 111 & 3.04 & $\begin{array}{l}\text { Posttranslational modification, protein } \\
\text { turnover, chaperones }\end{array}$ \\
\hline C & 233 & 6.38 & Energy production and conversion \\
\hline G & 259 & 7.10 & Carbohydrate transport and metabolism \\
\hline $\mathrm{E}$ & 525 & 14.38 & Amino acid transport and metabolism \\
\hline $\mathrm{F}$ & 86 & 2.36 & Nucleotide transport and metabolism \\
\hline $\mathrm{H}$ & 164 & 4.49 & Coenzyme transport and metabolism \\
\hline I & 120 & 3.29 & Lipid transport and metabolism \\
\hline$P$ & 261 & 7.15 & Inorganic ion transport and metabolism \\
\hline Q & 98 & 2.68 & $\begin{array}{l}\text { Secondary metabolites biosynthesis, } \\
\text { transport and catabolism }\end{array}$ \\
\hline $\mathrm{R}$ & 440 & 12.05 & General function prediction only \\
\hline S & 257 & 7.04 & Function unknown \\
\hline- & 858 & 20.91 & Not in COGs \\
\hline
\end{tabular}

$H$. alkalilenta $\mathrm{AW}-7^{\mathrm{T}}$ encodes the bioconversion of catechol and protocatechuate to $\beta$-ketoadipate via the $\beta$-ketoadipate and protocatechuate degradation II (ortho-cleavage) pathway respectively, as verified by the ability of strain $\mathrm{AW}-7^{\mathrm{T}}$ to catabolize certain phenolic compounds. Aerobic benzoate degradation I is also encoded, permitting its catabolism via the catechol degrading pathway. Genes encoding fluoroacetate dehalogenase were identified in the genome of $H$. alkalilenta $\mathrm{AW}-7^{\mathrm{T}}$, indicating its ability for fluoroacetate degradation. The detection of genes involved in cyanate and acrylonitrile degradation was also verified. Lastly, $H$. alkalilenta $\mathrm{AW}-7^{\mathrm{T}}$ is genetically able to produce ectoine and glycine betaine, which appear to serve as the main osmolytes for the adaptation of this species under high osmotic conditions.

Based on genome metabolic features, $H$. alkalilenta $\mathrm{AW}-\mathrm{7}^{\mathrm{T}}$ is prototrophic for L-arginine, L-histidine, Lisoleucine, L-leucine, L-lysine, L-phenylalanine, L- 
tryptophan, L-tyrosine and L-valine auxotroph, and Laspartate, L-glutamate, L-glutamine and glycine. Strain AW $-7^{\mathrm{T}}$ can synthesize selenocysteine but not biotin.

\section{Conclusions}

Genome sequence and biochemical data of the highly osmotolerant species Halotalea alkalilenta $\mathrm{AW}-7^{\mathrm{T}}$ revealed the presence of an oxidative phosphorylation pathway that lacks cytochrome $\mathrm{c}$ oxidase, and the encoding of the pyruvate fermentation to acetate II (MetaCyc pathway). H. alkalilenta $\mathrm{AW}-7^{\mathrm{T}}$ could ferment glucose and ducitol after a prolonged incubation period, which is indicative of the induction of a slow fermentation mechanism, and results in the emendation of the genus Halotalea Ntougias et al. 2007. Comparisons to its closest phylogenetic relatives Zymobacter palmae $\mathrm{T}_{109^{\mathrm{T}}}$ and Carnimonas nigrificans $\mathrm{CTCBS}^{\mathrm{T}}$, confirm the distinct taxonomic position of $H$. alkalilenta AW-7 on the basis of its larger genome size and number of protein coding genes involved in the major functional categories and in xenobiotics metabolism. Furthermore, $H$. alkalilenta $\mathrm{AW}-7^{\mathrm{T}}$ encodes the biotransformation of catechol and protocatechuate to $\beta$-ketoadipate via the $\beta$ ketoadipate and protocatechuate degradation II (orthocleavage) pathway respectively, verifying at the genome level the ability of strain $\mathrm{AW}-7^{\mathrm{T}}$ to degrade phenolic compounds.

\section{Emended description of the genus Halotalea Ntougias et al. 2007}

The description of the genus Halotalea is the one given by Ntougias et al. 2007 [1], with the following modification: Facultative anaerobe, which exhibits delayed glucose and dulcitol fermentation ability, and lacks cytochrome c oxidase activity.

\section{Abbreviations}

KMG: One thousand microbial genomes; GEBA: Genomic encyclopedia of Bacteria and Archaea; MIGS: Minimum information about a genome sequence; TAS: Traceable; NAS: Non-traceable.

\section{Competing interests}

The authors declare that they have no competing interests.

\section{Authors' contributions}

SN and GIZ performed the fermentation tests, conducted the phylogenetic analyses and drafted the paper, CF prepared the electron micrographs, and all other authors were involved in either sequencing/annotation of the genome and/or editing the paper. All authors read and approved the final manuscript.

\section{Acknowledgements}

This work was performed under the auspices of the US Department of Energy Office of Science, Biological and Environmental Research Program, and by the University of California, Lawrence Berkeley National Laboratory under contract No. DE-AC02-05CH11231, A.L. was supported in part by Russian Ministry of Science Mega-grant no.11.G34.31.0068 (PI. Dr Stephen J O'Brien).

\section{Author details}

${ }^{1}$ Laboratory of Wastewater Management and Treatment Technologies, Department of Environmental Engineering, Democritus University of Thrace, Xanthi, Greece. ${ }^{2}$ Theodosius Dobzhansky Center for Genome Bioinformatics, St. Petersburg State University, St. Petersburg, Russia. ${ }^{3}$ Algorithmic Biology Lab, St. Petersburg Academic University, St. Petersburg, Russia. ${ }^{4}$ Department of Energy Joint Genome Institute, Genome Biology Program, Walnut Creek, CA, USA. ${ }^{5}$ Biological Data Management and Technology Center, Lawrence Berkeley National Laboratory, Berkeley, CA, USA. ${ }^{6}$ Leibniz Institute DSMZ German Collection of Microorganisms and Cell Cultures, Braunschweig, Germany. ${ }^{7}$ Electron Microscopy Laboratory, Agricultural University of Athens, Athens, Greece. ${ }^{8}$ Department of Biological Sciences, Faculty of Science, King Abdulaziz University, Jeddah, Saudi Arabia. ${ }^{9}$ Laboratory of General and Agricultural Microbiology, Agricultural University of Athens, Athens, Greece.

Received: 23 December 2014 Accepted: 28 July 2015

Published online: 13 August 2015

\section{References}

1. Ntougias S, Zervakis GI, Fasseas C. Halotalea alkalilenta gen. nov., sp. nov., a novel osmotolerant and alkalitolerant bacterium from alkaline olive mill wastes, and emended description of the family Halomonadaceae Franzmann et al. 1989, emend. Dobson and Franzmann 1996. Int J Syst Evol Microbiol. 2007;57:1975-83.

2. Franzmann PD, Wehmeyer U, Stackebrandt E. Halomonadaceae fam. nov., a new family of the class Proteobacteria to accommodate the genera Halomonas and Deleya. Syst Appl Microbiol. 1988;11:16-9.

3. Dobson SJ, Franzmann PD. Unification of the genera Deleya (Baumann et al. 1983), Halomonas (Vreeland et al. 1980), and Halovibrio (Fendrich 1988) and the species Paracoccus halodenitrificans (Robinson and Gibbons 1952) into a single genus, Halomonas, and placement of the genus Zymobacter in the family Halomonadaceae. Int J Syst Bacteriol. 1996:46:550-8.

4. Ben Ali Gam Z, Abdelkafi S, Casalot L, Tholozan JL, Oueslati R, Labat M. Modicisalibacter tunisiensis gen. nov., sp. nov., an aerobic, moderately halophilic bacterium isolated from an oilfield-water injection sample, and emended description of the family Halomonadaceae Franzmann et al. 1989 emend Dobson and Franzmann 1996 emend. Ntougias et al. 2007. Int J Syst Evol Microbiol. 2007;57:2307-13.

5. Vreeland RH, Litchfield CD, Martin EL, Elliot E. Halomonas elongata, a new genus and species of extremely salt-tolerant bacteria. Int J Syst Bacteriol. 1980;30:485-95.

6. Ventosa A, Gutierrez MC, Garcia MT, Ruiz-Berraquero F. Classification of 'Chromobacterium marismortui' in a new genus, Chromohalobacter gen. nov., as Chromohalobacter marismortui comb. nov., nom. rev. Int J Syst Bacteriol. 1989;39:382-6.

7. Okamoto T, Taguchi H, Nakamura K, Ikenaga H, Kuraishi H, Yamasato K. Zymobacter palmae gen. nov., sp. nov., a new ethanol-fermenting peritrichous bacterium isolated from palm sap. Arch Microbiol. 1993;160:333-7.

8. Garriga M, Ehrmann MA, Arnau J, Hugas M, Vogel RF. Carnimonas nigrificans gen. nov., sp. nov., a bacterial causative agent for black spot formation on cured meat products. Int J Syst Bacteriol. 1998;48:677-86.

9. Arahal DR, Castillo AM, Ludwig W, Schleifer KH, Ventosa A. Proposal of Cobetia marina gen. nov., comb. nov., within the family Halomonadaceae, to include the species Halomonas marina. Syst Appl Microbiol. 2002;25:207-11.

10. Anan'ina LN, Plotnikova EG, Gavrish EY, Demakov VA, Evtushenko LI. Salinicola socius gen. nov., sp. nov., a moderately halophilic bacterium from a naphthalene-utilizing microbial association. Mikrobiologiya. 2007;76:324-30.

11. Sanchez-Porro C, de la Haba RR, Soto-Ramirez N, Marquez MC, Montalvo-Rodriguez R, Ventosa A. Description of Kushneria aurantia gen. nov., sp. nov., a novel member of the family Halomonadaceae, and a proposal for reclassification of Halomonas marisflavi as Kushneria marisflavi comb. nov., of Halomonas indalinina as Kushneria indalinina comb. nov. and of Halomonas avicenniae as Kushneria avicenniae comb. nov. Int J Syst Evol Microbiol. 2009;59:397-405.

12. Wang $Y$, Tang S-K, Lou K, Lee J-C, Jeon CO, Xu L-H, et al. Aidingimonas halophila gen. nov., sp. nov., a moderately halophilic bacterium isolated from a salt lake. Int J Syst Evol Microbiol.

2009;59:3088-94 
13. León MJ, Sánchez-Porro C, de la Haba RR, Llamas I, Ventosa A. Larsenia salina gen. nov., sp. nov., a new member of the family Halomonadaceae based on multilocus sequence analysis. Syst Appl Microbiol. 2014;37:480-7.

14. León MJ, Sánchez-Porro C, de la Haba RR, Llamas I, Ventosa A. Corrigendum to Larsenia salina gen. nov., sp. nov., a new member of the family Halomonadaceae based on multilocus sequence analysis [Syst. Appl. Microbiol., 37 (October (7)) (2014) 480-487]. Syst Appl Microbiol. 2015;38:77.

15. Oren A, Garrity GM. List of new names and new combinations previously effectively, but not validly, published. Int J Syst Evol Microbiol. 2015:65:1105-11.

16. de la Haba RR, Carmen Márquez M, Thane Papke R, Ventosa A. Multilocus sequence analysis (MLSA) of the family Halomonadaceae. Int J Syst Evol Microbiol. 2012:62:520-38.

17. DeSantis TZ, Hugenholtz P, Larsen N, Rojas M, Brodie EL, Keller K, et al. Greengenes, a chimera-checked 165 rRNA gene database and workbench compatible with ARB. Appl Environ Microbiol. 2006;72:5069-72.

18. Porter MF. An algorithm for suffix stripping. Program. 1980;14:130-137.

19. Klenk HP, Göker M. En route to a genome-based classification of Archaea and Bacteria? Syst Appl Microbiol. 2010;33:175-82.

20. Göker M, Klenk HP. Phylogeny-driven target selection for large-scale genome-sequencing (and other) projects. Stand Genomic Sci. 2013;8:360-74.

21. Wu D, Hugenholtz P, Mavromatis K, Pukall R, Dalin E, Ivanova NN, et al. A phylogeny-driven Genomic Encyclopaedia of Bacteria and Archaea. Nature. 2009:462:1056-60.

22. Kyrpides NC, Woyke T, Eisen JA, Garrity G, Lilburn TG, Beck BJ, et al. Genomic Encyclopedia of Type Strains, Phase I: the one thousand microbial genomes (KMG-I) project. Stand Genomic Sci. 2013;9:628-34.

23. Kyrpides NC, Hugenholtz P, Eisen JA, Woyke T, Göker M, Parker CT, et al. Genomic encyclopedia of Bacteria and Archaea: sequencing a myriad of type strains. PLOS Biol. 2014;8, e1001920

24. Reddy TB, Thomas AD, Stamatis D, Bertsch J, Isbandi M, Jansson J, et al. The Genomes OnLine Database (GOLD) v.5: a metadata management system based on a four level (meta)genome project classification. Nucleic Acids Res. 2015:43(Database issue):D1099-106.

25. DOE Joint Genome Institute. [http://www.jgi.doe.gov]

26. Mavromatis K, Land ML, Brettin TS, Quest DJ, Copeland A, Clum A, et al. The fast changing landscape of sequencing technologies and their impact on microbial genome assemblies and annotation. PLoS One. 2012;7, e48837.

27. Gemeinholzer B, Dröge G, Zetzsche H, Haszprunar G, Klenk HP, Güntsch A et al. The DNA Bank Network: the start from a German initiative. Biopreserv Biobank. 2011:9:51-5.

28. Bennett S. Solexa Ltd. Pharmacogenomics. 2004;5:433-8.

29. JGI Website. [http://www.jgi.doe.gov].

30. Zerbino D, Birney E. Velvet: algorithms for de novo short read assembly using de Bruijn graphs. Genome Res. 2008;18:821-9.

31. Wgsim. [https://github.com/lh3/wgsim]

32. Gnerre S, MacCallum I. High-quality draft assemblies of mammalian genomes from massively parallel sequence data. Proc Natl Acad Sci U S A. 2011;108:1513-8.

33. Hyatt D, Chen GL, Locascio PF, Land ML, Larimer FW, Hauser L. Prodigal: Prokaryotic gene recognition and translation initiation site identification. BMC Bioinformatics. 2010;11:119.

34. Mavromatis K, Ivanova NN, Chen IM, Szeto E, Markowitz VM, Kyrpides NC. The DOE-JGI Standard operating procedure for the annotations of microbial genomes. Stand Genomic Sci. 2009;1:63-7

35. Chen IM, Markowitz VM, Chu K, Anderson I, Mavromatis K, Kyrpides NC, et al. Improving microbial genome annotations in an integrated database context. PLoS One. 2013;8, e54859.

36. Markowitz VM, Mavromatis K, Ivanova NN, Chen IM, Chu K, Kyrpides NC. IMG ER: a system for microbial genome annotation expert review and curation. Bioinformatics. 2009:25:2271-8.

37. Markowitz VM, Chen I-M A, Palaniappan K, Chu K, Szeto E, Grechkin Y, et al. IMG: the integrated microbial genomes database and comparative analysis system. Nucleic Acids Res. 2012;40:D115-22.

38. Lee C, Grasso C, Sharlow MF. Multiple sequence alignment using partial order graphs. Bioinformatics. 2002;18:452-64.

39. Castresana J. Selection of conserved blocks from multiple alignments for their use in phylogenetic analysis. Mol Biol Evol. 2000;17:540-52.
40. Stamatakis A, Hoover P, Rougemont J. A rapid bootstrap algorithm for the RAxML web servers. Syst Biol. 2008:57:758-71.

41. Tamura K, Stecher G, Peterson D, Filipski A, Kumar S. MEGA6: Molecular evolutionary genetics analysis version 6.0. Mol Biol Evol. 2013:30:2725-9.

42. Field D, Garrity GM, Gray T, Morrison N, Selengut J, Sterk P, et al. The minimum information about a genome sequence (MIGS) specification. Nat Biotechnol. 2008;26:541-7.

43. Field D, Amaral-Zettler L, Cochrane G, Cole JR, Dawyndt P, Garrity GM, et al The Genomic Standards Consortium. PLoS Biol. 2011;9, e1001088.

44. Garrity GM. Names for Life. Browser Tool takes expertise out of the database and puts it right in the browser. Microbiol Today. 2010;37:9.

45. Woese CR, Kandler O, Wheelis ML. Towards a natural system of organisms: proposal for the domains Archaea, Bacteria, and Eucarya. Proc Natl Acad Sci U S A. 1990;87:4576-9.

46. Garrity GM, Bell JA, Lilburn T. Phylum XIV. Proteobacteria phyl. nov. In: Brenner DJ, Krieg NR, Staley JT, Garrity GM, editors. Bergey's Manual of Systematic Bacteriology. Volume 2, part B. 2nd ed. New York: Springer; 2005. p. 1.

47. Validation List no. 106. Validation of publication of new names and new combinations previously effectively published outside the IJSEM. Int J Syst Evol Microbiol. 2005;55:2235-8.

48. Garrity GM, Bell JA, Lilburn T. Class III. Gammaproteobacteria class. nov. In: Brenner DJ, Krieg NR, Staley JT, Garrity GM, editors. Bergey's Manual of Systematic Bacteriology. Volume 2, part B. 2nd ed. New York: Springer; 2005. p. 1

49. Williams KP, Kelly DP. Proposal for a new class within the phylum Proteobacteria, Acidithiobacillia classis nov., with the type order Acidithiobacillales, and emended description of the class Gammaproteobacteria. Int I Syst Evol Microbiol. 2013:63:2901-6.

50. Garrity GM, Bell JA, Lilburn T. Order VIII. Oceanospirillales ord. nov. In: Brenner DJ, Krieg NR, Staley JT, Garrity GM, editors. Bergey's Manual of Systematic Bacteriology. Volume 2, part B. 2nd ed. New York: Springer; 2005. p. 270

51. Validation List no. 29. Validation of the publication of new names and new combinations previously effectively published outside the IJSB. Int J Syst Bacteriol. 1989;39:205-6.

52. Bundesanstalt für Arbeitsschutz und Arbeitsmedizin (BAuA). Classification of prokaryotes (bacteria and archaea) into risk groups. Germany: Technical Rule for Biological Agents 466 (TRBA 466); 2010. p. 157.

53. Ashburner M, Ball CA, Blake JA, Botstein D, Butler H, Cherry JM, et al. Gene ontology: tool for the unification of biology. The Gene Ontology Consortium. Nat Genet. 2000:25:25-9.

\section{Submit your next manuscript to BioMed Central and take full advantage of:}

- Convenient online submission

- Thorough peer review

- No space constraints or color figure charges

- Immediate publication on acceptance

- Inclusion in PubMed, CAS, Scopus and Google Scholar

- Research which is freely available for redistribution

Submit your manuscript at www.biomedcentral.com/submit
C) Biomed Central 